\title{
Promoting the Construction of the Experiment Center of School of Optical-electrical and Computer Engineering through ASIIN Accreditation
}

\author{
Yujun Tang ${ }^{1, a}$, Boqing $X u^{1, b}$, Xiangmei Dong ${ }^{1, c}$, Niyong Shen ${ }^{1, d}$
}

1 University of Shanghai for Science and Technology, 516 Jungong Road, Shanghai, China

a yujtang@gmail.com, ${ }^{\mathrm{b}}$ xuboqing@usst.edu.cn, ${ }^{\mathrm{C}} \mathrm{dxm} 77 @$ @usst.edu.cn,

d13611855384@163.com

\begin{abstract}
Keywords: ASIIN, Accreditation, Experiment Center, Construction, Promote
Abstract. With the increasing of the international education communication, many local universities are studying the overseas professional training mode, emphasizing the practice and innovation. In order to make our education level meet the international standards, and provide students a better platform to practice, it is urgent to enhance the construction of the experiment center. Through ASIIN, we improved the whole quality of the experiment center from the aspects including the laboratory resources, experiment contents, experiment management and teachers.
\end{abstract}

\section{Introduction}

With the development of economic globalization, the international trend of higher engineering education is more and more obvious, professional accreditation has become an inevitable topic for an international engineering education. According to the development strategy of education internationalization and best quality of undergraduate courses, in November 2013, the specialist group of ASIIN (German Accreditation Agency for Study Programs in Engineering, Informatics, Natural Sciences and Mathematics), ${ }^{[1]}$ the German authoritative institution, visted the "Photoelectric Information Engineering" of OECE(School of Optical-Electrical and Computer Engineering) of USST(University of Shanghai for Science and Technology), which is the most important step in the process of accreditation. The undergraduate engineering, which is completely set up and managed by the Chinese university, met the international certification agency in accordance with international standards. And it has actively echoed the new trend of that, the domestic university engineering joined in the international engineering union, Washington Accord. ${ }^{[2]}$ And in 2011, the master program of "Measuring and Testing Technology and Instruments" of OECE has passed the certification of ASIIN. Through ASIIN accreditation, OECE aimed at improving the quality of the international education, also setting up a demonstration effect for other departments of OECE.

OECE is composed of Optical Information College, Computer Science and Engineering College and Electrical Engineering College a few years ago. Obviously, the goal of the combination of three colleges is to enhance the teaching and scientific research work. During the first three years of the merger, the undergraduate teaching was integrated into 10 undergraduate majors from the first 13 undergraduate majors. Also some of the experiment center resources have been reassigned, and which has made an obvious progress. The further reform of teaching, as well as the international communication, has raised new requirements on how to further improve the quality and efficiency of undergraduate teaching, especially with regard to the construction of experiment center. ASIIN accreditation has promoted the integration of the resources, the management and team construction of experiment center, and also has enriched the whole level and quality of experimental teaching, therefore to achieve the goal of "Promoting Construction, Reforming and Management through Accreditation".

\section{Brief Introduction of ASIIN}

ASIIN is a German accreditation agency for degree programs in engineering, informatics, natural science and mathematics. ${ }^{[1]}$ ASIIN is the most authoritative accreditation institution for higher education degree program in natural engineering in Germany. Also it is an authoritative 
accreditation institution for international degree program. At the same time, it is a preparatory member of Washington Accord, which is an international accreditation agreement for professional engineering academic degrees. ${ }^{[2]}$ And it is a member and also the founder of the accreditation system of European engineering educational project for degree program. Without studying go abroad, the graduates of the higher education institution which has passed the ASIIN accreditation, will obtain the title of "European engineers".

The goal of ASIIN accreditation is that, not only make the students meet the knowledge progress, but also enable them to obtain the necessary ability for success in their chosen field and lifelong learning ability. Through the program applied for accreditation, the students will master solid basic theory, sound professional knowledge and outstanding ability of practices. Meanwhile the students would understand the social responsibility and ethics, will have the ability continue learning and will be competitive in the international environment after graduation. ${ }^{[2]}$

\section{Promoting Construction, Reform and Construction of Experiment Center Through Accreditation}

Integration of Laboratory Resources. In the merger of three colleges, the utilization efficiency of laboratory resources is much low which surfaced the reality that multiple similar or identical Labs are duplicated in different departments, however due to limited budget and accommodation, their scopes are inadequate. Moreover, because of self-construction of different departments, with different brand, type of same equipment, an unreasonable phenomenon was led that some Labs are repeatedly opened to meet the demands of education, while the others are quite vacant. Hence some teachers are too busy to work, and others are much idle.

Thus the experiment center should have an overall planning, unified arrangement, deployment, leveraging the experimental teaching and related resources, to maximize the resources sharing. Position setting, budget allocation should also in accordance with overall consideration. The experiment center resources integration work content mainly includes the following two aspects.

Unifying the Identical Content of Laboratory Resources for Comprehensive Utilization. The same content of laboratory resources integration is that the laboratory resources of the same experiment course in different major integrated together. Such as, the lab resources of "Microcomputer Principle Series Experiment" and "MCU (Micro Controller Unit) Series Experiment" are same, so without any increase in funding for these cases, integration enlarged the experimental capacity, and could satisfy the demands of the college students' course selection. Previous professional teachers were overall arranged, to avoid the waste of resources and personnel idling.

Integrate Similar Content of Laboratory Resources for Composite Utilization. Similar laboratory resources integration is the experiment content in the form of different, but the experiment form relevant laboratory resources integration in together. Actually, through long-term experience and analysis of the experimental courses, we found that the photoelectric college has quite many of experiments although content is different, but basically the same in the form of experimental conditions. For example, "Signal and System", "Photoelectric Measurement and Control Technology" and "Automatic Control Principle" experiments, in which the instruments and equipment are the same, but just differences in the experimental objects. These kinds of experiments may combine together therefore to maximize the utilization of the instruments and equipment.

Because of the integration of laboratory resources is particularly subject to the conditions of laboratory space, the integration of experimental resources is difficult to accomplish in a short time. Now it requires full analysis of the existing experiment course, experiment equipment, distribution of experiment teachers and the students to participate in the experiment, so in the future, the condition, according to the practical experiment courses, will gradually improve.

Experiment Forms Diversity and Flexibility. Combining with the characteristics of discipline, for the cultivation of innovation and comprehensive skills of students, each experiment course has at least two practical or composition experiments. Students are supposed to actively participate in the 
process of experimental preparation and design experiment, especially some comprehensive experiments, teachers is only enlightening to guide the student, and students have to find information, carries on the analysis, understanding and carry on the experimental operation to success by their own, eventually they need to submit a formal experiment report, which contains information consulting, self-analysis, instead of experimental measurement data. This is to prevent unprepared students from only following the teacher step by step, hence to cultivate the good habit of self-independence.

Experiment Operation Mechanism. OECE plans to open the discipline laboratory and undergraduate laboratory through the international certification, and reform the experimental education system and the experiment link. Experiment center will open all laboratories, the experiments are given priority to practical design, innovation, and to make it results-oriented as examination standard. Undergraduate students can go to the interested discipline laboratories involved in the real discipline project, to enjoy the result of discipline construction. The master students are also enabled to use experimental resources, and do some validation, self-design experiments in the undergraduate laboratories, to lay a solid foundation for real projects implementation.

So the experiment center is perfecting its operation mechanism, aiming to provide students a personalized experiment system, allowing the student to make their own initiatives, to do experiments with flexibility.

Content Open. Reorganizing the content into a menu, so students can choose to do they want, especially some training classes. As in the electrician training, contents selection menu can be created like the following format.

Table 1 Electrician Training Selection Contents

\begin{tabular}{|l|l|}
\hline $\begin{array}{l}\text { Comprehensive Application } \\
\text { Type(choosing three in five) }\end{array}$ & $\begin{array}{l}\text { Timing Circuit, Four People Answering Circuit, DC } \\
\text { Voltage Measurement Circuit, A/D Conversion Circuit, } \\
\text { Two Different Signals Selection Circuit }\end{array}$ \\
\hline Research Type(choosing two in four) & $\begin{array}{l}\text { EUROTHERM Controller 514c Application, Application } \\
\text { of SIEMENS Inverter 440, AC Variable Frequency Speed } \\
\text { Control System of Industrial Washing Machine, Phase } \\
\text { Control Rectifier }\end{array}$ \\
\hline $\begin{array}{l}\text { Comprehensive Training Design } \\
\text { Type( choosing three in nine) }\end{array}$ & $\begin{array}{l}\text { Tree-phase Transformer Connection and Testing, Set-up/ } \\
\text { down DC Chopper Circuit Debugging, Full-controlled } \\
\text { Bridge Rectifier Circuit Connection and Debugging, }\end{array}$ \\
& $\begin{array}{l}\text { Half -Controlled Bridge Rectifier Circuit Connection and } \\
\text { Debugging, Phase Control Rectifier 1, Phase Control } \\
\text { Rectifier 2, Phase Control Rectifier 3, Electronic } \\
\text { Technology 1, Electronic Technology 2 }\end{array}$ \\
\hline
\end{tabular}

Flexible Time and Open Equipment. To improve the experiment reservation on-line system, through which teachers can choose proper laboratory based on student number, and students can choose their laboratory content in preferred timeframe more accordingly. Experiment booking system complies with the principle of first-choice-first-get to determine the experiment content and timeframe, all chosen courses information and statistics are recorded in system.

At the same time, students can choose the lab at a reserved time to finish their design and creative experiments. While the experiment center, according to reservation system, may provide the corresponding equipment, arrangement of the teachers for instruction.

Building of Experiment Team. Trough ASIIN accreditation, it is an urgent need to improve the quality of the whole experiment center teachers. The experiment center is strengthening itself through multiple ways, such as let the sophisticated professional theories teachers with advanced education background to arrange the experiment contents, allowing introducing their research subjects into the experiments, and revising the experimental outline in both Chinese and English. All of that will make the experiment content to keep the pace with times. It's also possible to create 
a training and evaluation plan for experimental teachers. They will train in batch. And the excellent teachers are granted further education opportunities and encouraged to apply for research topics to start the professional work. Meantime, it's required to adjust the policy to improve the treatment of teachers, to incite their initiatives. The specialized teachers in experiment teaching will enjoy certain degree of preferential, when they apply for high title. And the teachers will be encouraged to design more innovative, comprehensive and skillful experiments. Those who have good feedback from students with their original and creative experiments will be rewarded, and these experiments will be considered as part of criteria of examination and title assessment.

Experiment teachers themselves also should constantly strengthen their learning, absorbing the new knowledge of scientific researches and teachings, actively update experiment contents, improve teaching methods, allow the students who are interested in subject and can actively participate in the experiment, thus to cultivate students' creativity as much as possible.

\section{Conclusion}

Through ASIIN accreditation, as well as the requirement of high-level talents with more relevant quality, capability and knowledge structure in nowadays society, OECE started a new training program science 2010. It aims to be fully implemented in 10 undergraduate majors with professional training mode of " $3+1$ ", demanding students to finish their theoretic courses teaching in three years, in the fourth year to choose either internship in companies or doing academic research. It's more compelling for us to renew our education concept, focusing the importance of the cultivation of students' engineering practical ability. In the future, the experiment center will be continuously improving the laboratory layout, to further strengthen the management of the experiment resources, to enhance the innovative experiment content, and to improve the quality of experiment teachers. We are targeting to build the center as a "theory - practice - innovation" ${ }^{[3]}$ big platform for engineering oriented compound talents.

\section{References}

[1] Information on http://www.asiin-ev.de/pages/en/asiin-e.-v.php

[2] Information on http://en.wikipedia.org/wiki/Washington_Accord

[3] Jun Wang, Geng Yang, Changshui Zhang, in: Exploration of Undergraduate Experimental Teaching System and Laboratory Management Mode for Automation Discipline, Research and Exploration in Laboratory, Vol. 27 No.7 (Jul. 2008)

[4] Yuxin Zhao, Jianshi Zhang, The System and the Accreditation of German Engineering Education, in: Science Times ( ${ }^{\text {th }}$. Jun. 2007).

[5] Tsinghua University Investigation Group of Engineering Education Accreditation, Investigation Report of Accreditation, Reform and Development for German Engineering Education, in: Research on Higher Engineering Education 2006(1).

[6] Dong Fan, Xiaoyun Wang, Kuijun Zhao, in: Strengthening the Construction and Management of Laboratory in Higher Education and Improvement on the quality of the Undergraduates, Research and Exploration in Laboratory 2004(4).

[7] Nengbiao Wu, Hong Tian, Ling Huang, Jian Zhong, Strengthening the Exploration and Practice on Undergraduate Education, in: Research and Exploration in Laboratory 2005(11).

[8] Junzhi He, The Problems and Solutions of the Construction on University Labrotary science the Undergraduate Teaching Level Assessment, in: Journal of Aayang Teachers College 2012(2).

[9] Yanli Miao, Yuhou Song, Reform on the Laboratory Management System and Improvement on the Laboratory Function, in: Experimental Technology and Management, Vol.24, No.3 (Mar. 2007). 